\title{
Analysis on the Influencing Factors and Strategies of Urban Residents' Participation in Community Activities
}

\author{
Junyu Wang \\ School of Social Development, Tianjin University of Technology, Tianjin 30000, China \\ 418482907@qq.com
}

Keywords: urban residents, community participation, influencing factors, Strategies

\begin{abstract}
Community, as one of the habitations of urban residents, carries the multiple functions of production and living, while the attachment to community of its residents, as the main bodies constituting the community, is an important index testing the development of it. The research is mainly composed of interviews, discussing the factors influencing the participation of residents in the community from subjectivity and communal characteristic, through cultivating the residents' participation consciousness, improving the community service spirit and strengthening legal construction among other measures, to improve the involvement of community residents and enhance the level of community development.
\end{abstract}

\section{Introduction}

The sustained improvement of the national economy witnessed people's increasing demands for life, entertainment and consumption. As an important form for human to dwell, communities have the functions of production and everyday life. While being attached to the community, the individuals' requirements for diversity is also increasing day by day. However, due to the constraints of economic, spatial, geographical and other conditions, the problems existing in the urban residents' demands for and participation in community activities are still not effectively solved. In order to further understand the status quo of urban residents' participation in community activities, in this study, mainly analyzes its influencing factors mainly from the levels of the subjects themselves and the community.

\section{Analysis of influencing factors of community residents' participation in community activities}

\subsection{Objective Factors}

After analyzing the data of surveys in S Community comprehensively, it was found that gender, age, marital status, education background, socioeconomic status and length of residence will affect the residents' participation in community activities, resulting in significant differences in attitudes towards and behaviors of community participation.If being analyzed from the aspects of marital status, education background and household income per capita, the survey data indicates that married and unmarried residents account for $82 \%$ and $18 \%$ of the total respondents respectively, 
from which it can be seen can see the fact that the enthusiasm of married residents is higher than that of unmarried residents; in terms of the education background, the residents with the education under junior high school, junior and senior high school, junior college, and university or even higher, occupy proportions of $14 \%, 40 \%, 33 \%$ and $13 \%$ respectively; as for the per capita household income, the percentage of community participation of residents with an income of 2,000 yuan or less is $12 \%$, residents with an income between 2,000 yuan and 4,000 yuan is $52 \%$, residents with an income between 4,000 yuan and 6,000 yuan is $20 \%$, and residents with an income of more than 6,000 yuan, which is usually regarded as the high-income population, is $16 \%$.

The duration of residence also has a significant influence on residents' participation in community activities. According to the survey data, 58\% participants have been living in $\mathrm{S}$ community for over 5 years, residents living there for less than 5 years but more than 3 years is $22 \%$, residents living there between 1 and 3 years is $12 \%$, and the residents living there for less than 1 year is only $8 \%$. It shows that the longer the residence time is, the higher residents' enthusiasm to participate in community activities will be.

\subsection{Community Factors}

Among all the influencing factors, community factors are the important elements that exist in the community itself. The main factors restricting the residents' participation of S Community are as follows: the diversity of community activities, the capacity to publicize, the organizing ability, the location and the choice of time. Through the survey, we know that $20 \%$ of the respondents think that the activities in S Community are monotonous in both content and organizational form; $10 \%$ of the respondents hold that the publicity is not inspiring enough; $13 \%$ of the respondents deem that the organizing ability is insufficient; $21 \%$ of the respondents do not think the locations are well selected; and the rest $36 \%$ can not agree with the choice of time. All the community factors of the S Community are reflected in these aspects. S Community's failure in selection of locations and times is also exposed in the interviews of many residents, who have expressed the willingness to participate in community activities, obviously, it is the inconvenient location and time that constrict their desire to get involved. Some residents reflect that the problems of S Community itself is the lack of the ability to organize activities and publicize, which to a certain extent, has affected their enthusiasm of participating in community activities.

\section{Countermeasures and suggestions for residents to participate in community activities}

\subsection{Cultivate consciousness of community, boost spirit of participation}

Consciousness of community is residents' psychological or spiritual activity, which is closely related to the development of community and it includes the identification of, inclusion of, dependency on, cohesion of and satisfaction with the community ${ }^{[1]}$. An affirmative and positive consciousness of community is very important for the long-term development of the community itself and the establishment of the harmonious relationship between community and residents. S Community should propose new methods that encourage residents to participate in community activities voluntarily, improve and strengthen the publicity of community participation consciousness, and popularize the importance and effectiveness of community participation, rather than adopt a mandatory or rewarding way to improve residents' awareness of community participation $^{[2]}$. Providing favorable conditions for publicity and preparations, will create a platform for residents in S Community to take part in various activities passionately, do their best to serve and contribute to the community and raise the community participation, thus the community can be developed in a better way ${ }^{[3]}$. 


\subsection{Improve services, enrich activity contents}

Quality of the community's services and activities will directly relate to the residents' responses to community activities. To improve and promote the residents' participation, S Community must strengthen the community service, enrich the contents of community activities, and always put the residents' interests in the first place while serving the residents ${ }^{[4]}$. In stead of Imposing their personal interests on the residents by defrauding others, the organizers, no matter when and where, should provide services and complete work in accordance with the actual situation, as well as for the common good. In order to actively improve community service and enrich the contents of community activities, S Community should balance the overall interests of the community and the interests of the residents as well, and adhere to the Top priority

of serving the residents.

\subsection{Improve the quality of community staff}

At present, the residents' indifferent attitude towards and low participation rate of community activities also have something to do with the quality of the community staff. When there is physical and mental exhaustion, some community staff will complain to the community residents about their troubles in work; due to the Feeling of self-superiority, they tend to belittle or bully the community residents. Community staff should in no case have conflicts with residents. When selecting community staff, besides the technical knowledge, their personal accomplishments and quality have to be taken into account. Only by continuously strengthening the moral cultivation and construction of the community staff team, and further improving their theoretical knowledge and practical ability, can they provide professional and high-quality services for the residents, thus greatly promoting the relationship between the community residents and the working staff.

\subsection{Strengthen the construction of legal system}

The construction of community legal system and community autonomy are important links in the development of urban communities. It is of great significance to promote community autonomy, standardize the way and content of residents' participation in community construction, guarantee community participation by legal norms, and realize orderly community construction and community development. With the maintenance and support of laws, residents can foster stronger trust and identity towards community activities. Therefore, the construction of legal system should be strengthened, and the various rights and safety of the residents in the community activities should be protected, so that the residents' participation in community activities is able to achieve more under the guidance of the legal system.

\section{Conclusion}

The factors that influence urban residents' community participation can be roughly divided into two aspects. One is the subjective factor, including gender, age, marital status, education background, socioeconomic status and length of residence; the other one is community factor, such as the richness of community activities, the capacity to publicize, the organizing ability, the location, the choice of time, etc.. In the absence of awareness of the common interests, the residents will lose the link with everyone else, and without the emotional dependence, it will be more difficult to make full use of the community's manpower and material resources for mutual assistance and voluntary action. In order to improve the status of residents' participation and promote the orderly development of the community, we should, first of all, cultivate community consciousness, shape 
the spirit of participation and cultivate the spirit of ownership, so that the community residents are able to participate in community activities consciously and actively, and serve the community to the best of their own strength; secondly, improve community services, enrich community activities, emphasize common interests, and attach importance to residents' interests; thirdly, promote staff's personal quality and service spirit, establish a close relationship between the community staff and the residents, and further enhance residents' willingness to participate in the community activities; ultimately, strengthen the foundation and guarantee of the construction of legal system, safeguard the rights and safety of the residents' active participation in the community activities, and encourage the residents to participate in the community activities more voluntarily. As a result, the close interactive relationship among community residents can be established, the effective public services can be provided, and the residents' participation and support of community activities can be further enhanced.

\section{References}

[1] Zhu Ying. A Research on the Attitude towards and Behavior of Urban Residents' Community Participation -- A Case Study of Residents of Baoji City[D]. Ningxia University, 2010

[2] Liu Haizhen. A Research on the Current Situation and the Influencing Factors of Urban Residents' Community -- A Case Study of SJ Street in Nanjing City[D]. Agricultural University of Nanjing, 2009

[3] Chen Fan. A Research on the Relationship between Community Consciousness and Community Participation of Urban Residents[D]. Sichuan Normal University, 2009

[4] Claude S. Fischer. Toward a Subcultural Theory of Urbanism. American Journal of Sociology, 1975(6). 